\title{
Case Report: An Acromegalic Patient Presented with Dysphagia
}

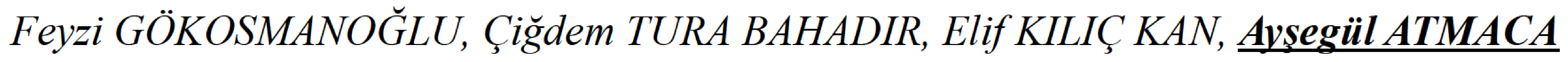

Ondokuz Mayis University School of Medicine

Department of Endocrinology and Metabolism

Samsun, TURKEY

\section{OBJECTIVES}

Acromegaly is a chronic disease characterized by prognatism, frontal bossing, coarsened facial features, enlarged hands and feet due to overproduction of growth hormone $(\mathrm{GH})$ generally by a pituitary adenoma. Here, we aimed to present an acromegalic patient presented with retropharyngeal hypertrophy first time in the literature.

\section{CASE REPORT}

Sixtyfive-year-old female patient had been referred to our department from otorhinolaryngology outpatient-clinic, where she had admitted with sensation of something stuck in throat for 2 years, upon finding overgrowth in uvula and orophayrngeal structures (Figure 1). She had symptoms of sweating, overgrowth in hands, feet, nose and lips. She had type 2 diabetes mellitus and hypertension history. Physical examination revealed coarsened facial features, deepened nasolabial folds, prognatism, tongue and oropharynx hypertrophy. Her blood glucose level was $173 \mathrm{mg} / \mathrm{dl}$, IGF-1 level was $929 \mathrm{ng} / \mathrm{dl}$ (normal range: 94-166 ng/dl) and GH level was $4.2 \mathrm{ng} / \mathrm{dl}$. The lowest GH level during growth hormone suppression test was $3.8 \mathrm{ng} / \mathrm{dl}$. Levels of other pituitary hormones were normal. Head and neck magnetic resonance imaging (MRI) revealed expansion of orofacial bones and hyperthropy of the retropharyngeal soft tissue (Figure 2). MRI of pituitary gland revealed a 8x6 mm microadenoma with well defined boundaries in the pituitary gland (Figure 3 ). The patient was diagnosed with acromegaly and consulted with neurosurgery department regarding surgery.

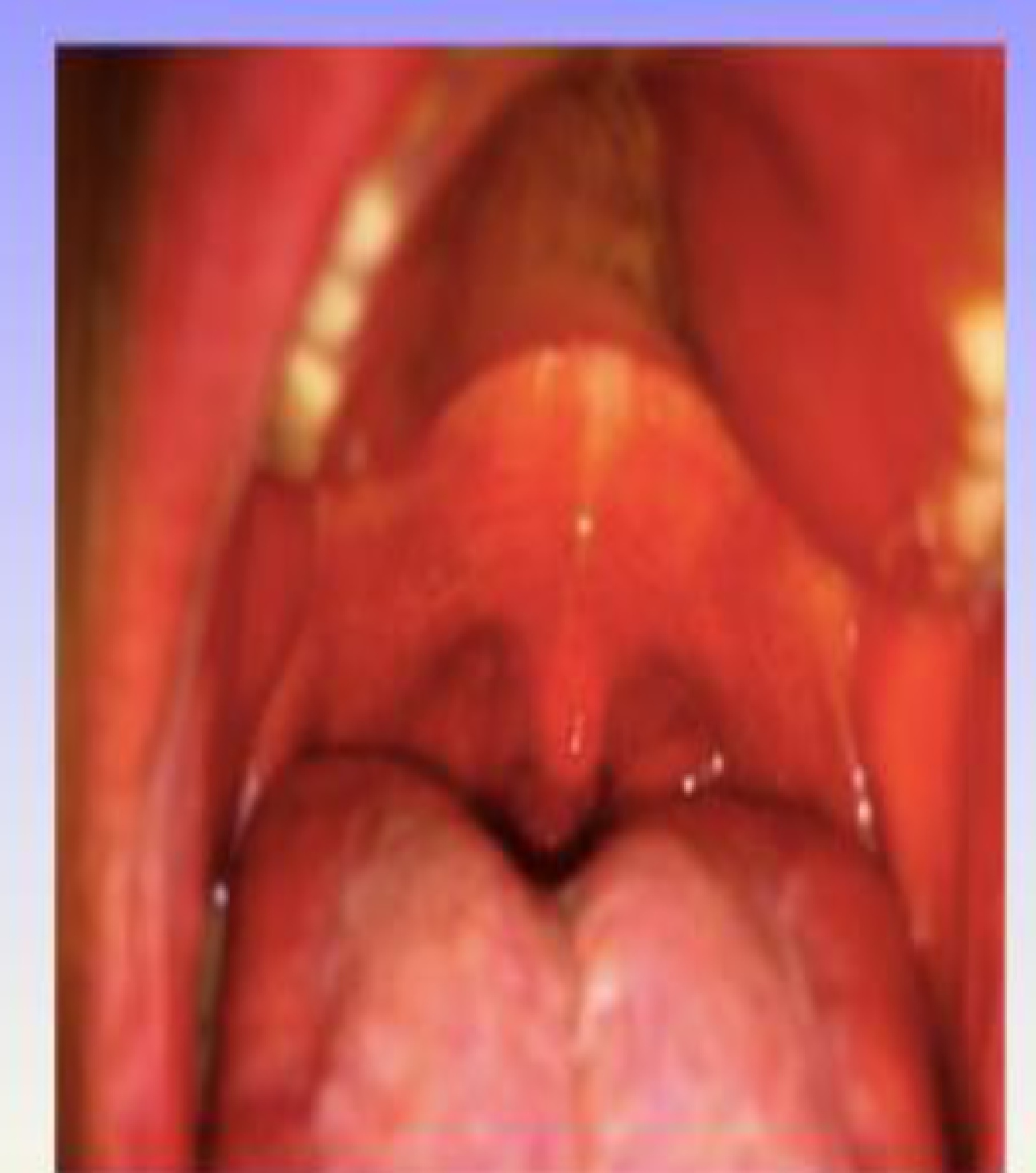

Figure 1: oropharynx hyperthrophy

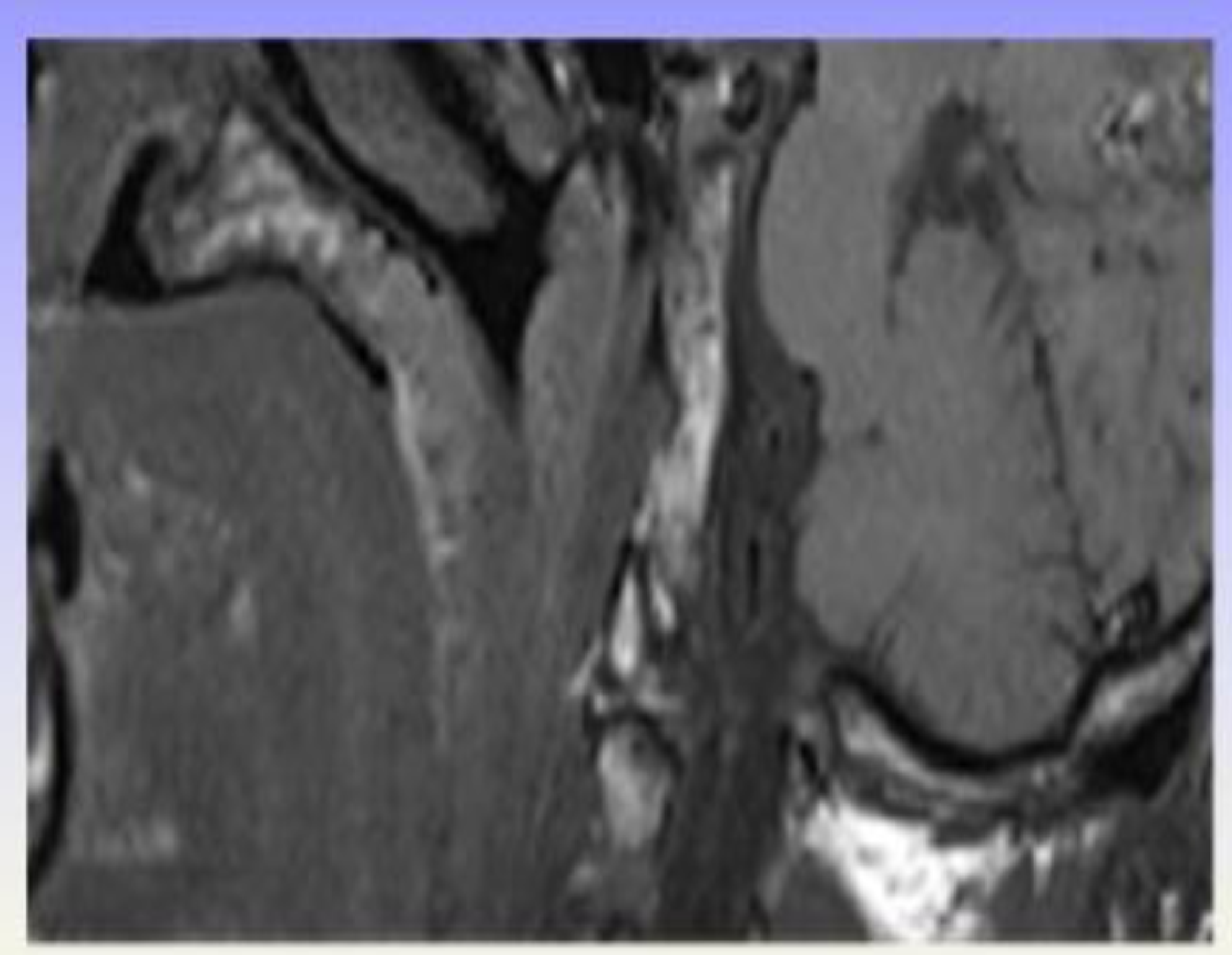

Figure 2:servical MRI

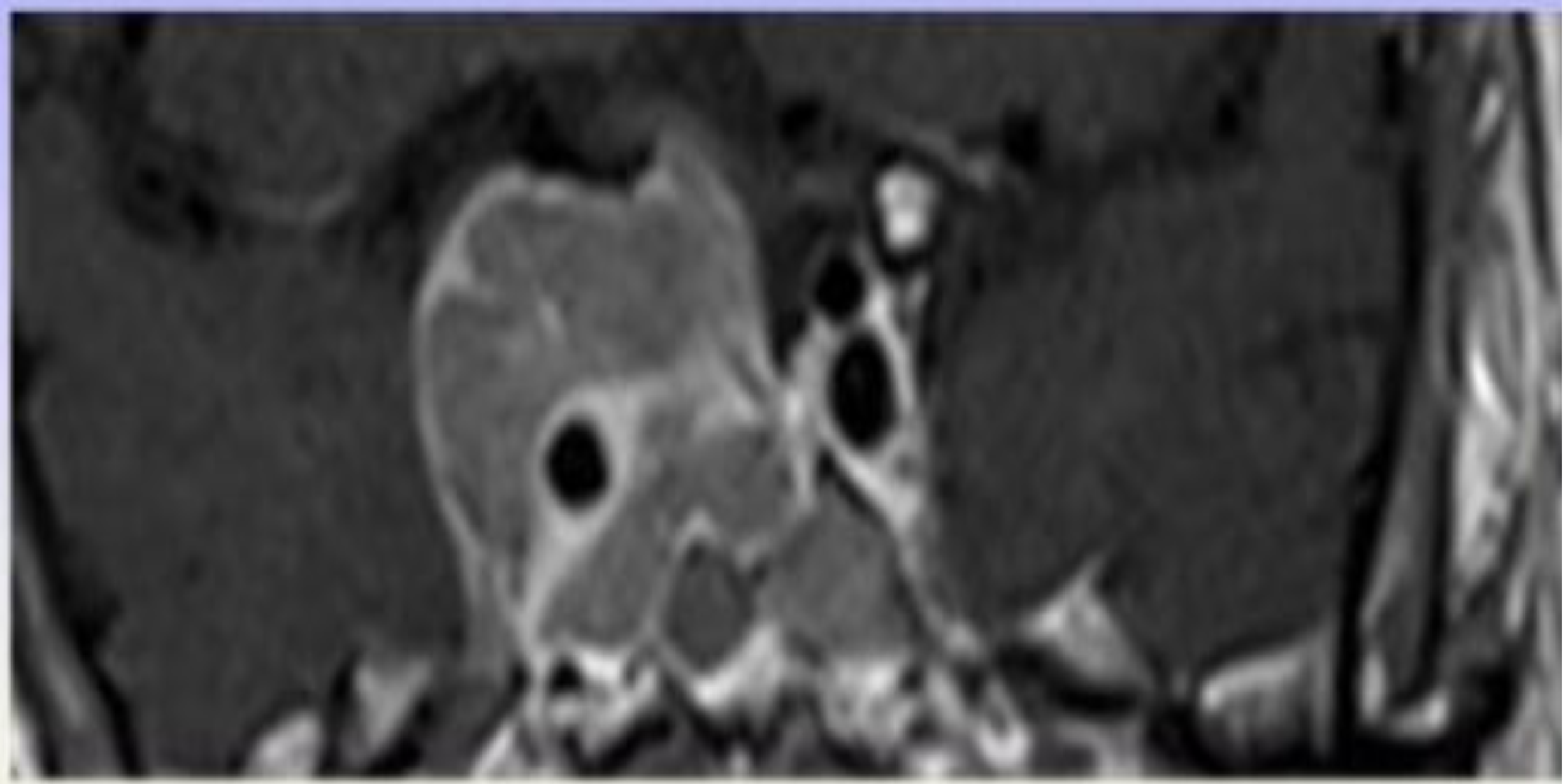

Figure 3: MRI of pituitary gland

\section{CONCLUSIONS}

Acromegaly is a condition that should be considered in cases of soft tissue hyperthrophy in oral cavity, teeth occlusions, diastema and teeth prosthesis discrepancies. 